\title{
Magnetic Resonance Coronary Angiography: Where Are We Today?
}

\author{
Amedeo Chiribiri • Rene M. Botnar • Eike Nagel
}

Published online: 11 January 2013

(C) The Author(s) 2013. This article is published with open access at Springerlink.com

\begin{abstract}
Although cardiovascular magnetic resonance allows the non-invasive and radiation free visualization of both the coronary arteries and veins, coronary vessel wall imaging is still undergoing technical development to improve diagnostic quality. Assessment of the coronary vessels is a valuable addition to the analysis of cardiac function, cardiac anatomy, viability and perfusion which magnetic resonance imaging reliably allows. However, cardiac and respiratory motion and the small size of the coronary vessels present a challenge and require several technical solutions for image optimization. Furthermore, the acquisition protocols need to be adapted to the specific clinical question. This review provides an update on the current clinical applications of cardiovascular magnetic resonance coronary angiography, recent technical advances and describes the acquisition protocols in use.
\end{abstract}

Keywords Coronary angiography $\cdot$ Coronary venous system $\cdot$ Gadolinium $\cdot$ Magnetic resonance imaging

\section{List of Abbreviations \\ 2D 2-dimensional \\ 3D 3-dimensional \\ CA contrast agent \\ CAD coronary artery disease \\ CMR cardiovascular magnetic resonance}

This article is part of the Topical Collection on Cardiac PET, CT, and MRI

A. Chiribiri $(\bowtie) \cdot$ R. M. Botnar $\cdot$ E. Nagel

Division of Imaging Sciences and Biomedical Engineering,

King's College London BHF Centre of Excellence,

NIHR Biomedical Research Centre and Wellcome Trust and EPSRC Medical Engineering Centre at Guy's and St. Thomas'

NHS Foundation Trust, The Rayne Institute,

4th Floor Lambeth Wing, St. Thomas' Hospital,

London SE1 7EH, UK

e-mail: amedeo.chiribiri@kcl.ac.uk

$\begin{array}{ll}\text { CT } & \text { computed tomography } \\ \text { CV } & \text { coronary veins } \\ \text { EPI } & \text { echo planar imaging } \\ \text { ICAM-1 } & \text { intercellular adhesion molecule - 1 } \\ \text { LAD } & \text { left anterior descending (coronary artery) } \\ \text { LCX } & \text { left circumflex (coronary artery) } \\ \text { MMP } & \text { matrix metalloproteinase } \\ \text { MRA } & \text { magnetic resonance angiography } \\ \text { MTC } & \text { magnetization transfer contrast } \\ \text { RCA } & \text { right coronary artery } \\ \text { SAR } & \text { specific absorption rate } \\ \text { SENSE } & \text { sensitivity encoding } \\ \text { SMASH } & \text { simultaneous acquisition of spatial harmonics } \\ \text { SNR } & \text { signal-to-noise ratio } \\ \text { SSFP } & \text { steady state free precession } \\ \text { USPIO } & \text { ultra-small super paramagnetic iron oxide } \\ \text { VCAM-1 } & \text { vascular adhesion molecule }-1\end{array}$

\section{Introduction}

Despite substantial improvements in prevention and treatment [1], coronary artery disease (CAD), myocardial infarction and heart failure constitute the leading cause of death in the western world [2]. The current gold standard for the diagnosis of CAD is invasive coronary angiography, but the increasing prevalence of $\mathrm{CAD}$ and the relatively reduced diagnostic yield of invasive assessment [3] clearly indicate the need for noninvasive tests that could directly assess the integrity of the coronary lumen [4].

Cardiovascular magnetic resonance (CMR) theoretically provides a combined approach allowing the assessment of coronary arteries, cardiac function, viability, perfusion and cardiac anatomy. Moreover, magnetic resonance angiography (MRA) can potentially be used to directly visualize the coronary vessel wall [5], providing valuable integrated information for patients with coronary artery disease. Additionally, 
coronary MRA techniques allow the visualization of the anatomy of the coronary veins $(\mathrm{CV})$, providing information for the optimal placement of pacemaker leads in cardiac resynchronization therapy in patients with heart failure $[6,7]$. This review provides an update on current technical developments and clinical utilization of coronary MRA.

\section{Indications for Coronary MRA}

Clinically accepted indications of coronary MRA are currently limited to the assessment of anomalies of the coronary arteries (class I indication) and aorto-coronary bypass grafts (class II indication). The use of MRA for the diagnosis of $\mathrm{CAD}$ on native coronary arteries has not yet entered clinical routine $[8,9]$.

\section{Coronary Anomalies and Aneurysms (Class I Indication)}

Coronary MRA can accurately visualize the origin and the path of anomalous coronary vessels, as well as the presence and location of coronary aneurysms. Aneurysms are found, for example, in Kawasaki disease. The usually larger caliber of the vessels and the location of the aneurysms in proximal or ectatic segments facilitate their visualization. An important added benefit of coronary MRA is the absence of ionizing radiation, particularly important in younger patients, children and young women $[8,10]$.

\section{Coronary Bypass-Grafts (Class II Indication)}

Bypass grafts can be visualized by coronary MRA with good image quality, benefiting from their stationary position, straight and known course, and large diameter compared to the coronary arteries. Several different approaches for the visualization of coronary bypass grafts were published in the literature, including spin echo [11-14] and gradient echo techniques. Moreover, the use of contrast agents for the enhancement of the blood signal $[15,16]$ allowed sensitivities for the detection of graft stenoses between $95 \%$ and $100 \%$.

However, the presence of metallic clips along the course of the graft, causing signal voids due to susceptibility artifacts, is a common limitation of coronary bypass MRA. According to current guidelines, coronary MRA may be used at specialized centers to identify stenoses in coronary arterial bypass grafts [8].

\section{Coronary Artery Angiography for the Detection of CAD}

Coronary MRA can visualize the proximal segments of the coronaries in nearly $100 \%$ of cases. The best results are obtained with the left anterior descending (LAD) and the right coronary artery (RCA), while the left circumflex (LCX), which runs in the direct vicinity of the myocardium and at a larger distance from the coil elements, is frequently visualized with lower image quality and for a shorter course.

Previous studies reported an average visible length of $50 \mathrm{~mm}$ for the LAD, $80 \mathrm{~mm}$ for the RCA and $40 \mathrm{~mm}$ for the LCX [17-23]. There was an excellent agreement between the diameters of the proximal vessels measured by MRA and by invasive angiography [24].

The spatial resolution of coronary MRA is still lower than that of invasive coronary angiography, which limits the visualization of small branches and affects diagnostic accuracy concerning stenosis detection. This limitation explains the low specificity demonstrated in a recent international multicenter study [4], whereby coronary MRA was shown to have a high sensitivity ( $92 \%$ ) and a low specificity $(59 \%)$ for the detection of CAD. The diagnostic performance was much improved in a subanalysis of left main or three vessel disease (sensitivity $100 \%$; negative predictive value $100 \%$ ). A series of smaller single-center studies support these findings [17, 25-33].

A recent meta-analysis compared coronary MRA and multi-slice computed tomography $(\mathrm{CT})$ for ruling out significant $\mathrm{CAD}$ in adults [34-]. CT was more accurate than MRA and therefore the authors concluded that $\mathrm{CT}$, in its role of screening for CAD, can be considered as the preferred non-invasive alternative method to coronary catheterization. However, the advantage of coronary MRA is that it could be part of an integrated clinical protocol (including function, structure, perfusion and viability scans), allowing a more accurate evaluation of patients with known or suspected CAD.

Moreover, a more recent multicenter study from Japan showed that non-contrast-enhanced whole-heart coronary MRA at $1.5 \mathrm{~T}$ can detect significant CAD with high sensitivity $(88 \%)$ and moderate specificity (72\%). In particular, a negative predictive value (NPV) of $88 \%$ indicates that whole heart coronary MRA can effectively be used to rule out CAD [35••]. Of note, the NPV reported by this multicenter trial is identical to the NPV of the CORE-64 CTA multicenter study [36], demonstrating the value of coronary MRA in ruling out coronary artery disease in patients with a pre-test probability of $<20 \%$ [37].

In a direct comparison between coronary MRA and CTA no significant difference was shown for the detection of coronary artery stenosis between $3 \mathrm{~T}$ MR and 64-slice CTA, although CTA showed a favorable trend toward higher diagnostic performance $[38 \bullet \bullet$.

\section{Coronary Vein Imaging}

With the advent of resynchronization therapy, the assessment of the anatomy of the coronary venous system has 
become increasingly important, particularly for the preinterventional identification of optimal placement site for the left ventricular lead of resynchronization devices. The same techniques used for coronary (artery) MRA can be used to visualize the coronary veins. Three-dimensional MR coronary vein angiograms can be overlaid onto real-time time acquired $\mathrm{x}$-ray images, to improve guidance for catheter implantation [39, 40].

The integration of coronary venous anatomy and myocardial scar information may also guide left ventricular lead implantation remote from areas of scanned myocardium. Contrast agent enhanced MR can be used for the assessment of the course of the coronary sinus, the great cardiac vein, and their tributaries $[6,7,41]$.

\section{Coronary Vessel Wall Imaging}

The first magnetic resonance images of the coronary vessel wall were obtained by $2 \mathrm{D}$ fat saturated fast spin echo techniques $[42,43]$. A double inversion recovery preparation is applied to obtain black-blood images improving the contrast between blood and vessel wall [44].

Recently, the double inversion recovery prepulse has been combined with fast gradient echo readout techniques [45], with spiral [46] and with radial acquisition trajectories [47].

Clinical studies demonstrated the ability of vessel wall imaging to detect outward positive remodeling with relative lumen preservation in patients with CAD and increased vessel wall thickness in patients with type I diabetes and renal dysfunction $[48,49]$. As shown by Jansen and colleagues, noncontrast enhanced T1-weighed MR allows direct thrombus visualization in patients with acute myocardial infarction [50].

It is of particular interest that there are approaches that may allow visualization of inflamed plaques by means of delayed gadolinium enhancement techniques. Clinically approved contrast agents showed non-specific uptake in plaques both in patients with chronic angina [51] and in patients with acute coronary syndromes [52] and also in patients with systemic lupus erythematosus as sign of coronary inflammation or vessel wall activity [53]. Contrast uptake in patients with stable angina was associated with calcified or mixed plaques on MSCT while contrast uptake in patients with ACS the contrast uptake was transient and so most likely related to inflammation.

Several novel target specific contrast agents have been developed and tested in animal models. The accumulation of albumin binding blood-pool CA is associated with increased endothelial permeability and/or increased neovascularization [19, 54]. Furthermore, increased accumulation of ironoxide particles (USPIO) also indicates increased endothelial permeability and vessel wall inflammation due to the presence of intraplaque macrophages $[55,56]$.
Such molecules and cells are providing targets for recently developed novel molecular contrast agents. These CA allow the selective visualization of inflammatory markers such as intercellular adhesion molecule-1 (ICAM-1), vascular adhesion molecule-1 (VCAM-1) or matrix metalloproteinase (MMP) [57, 58]. Additionally, the specific labeling of thrombi by a fibrin-specific contrast agent $[59,60]$ and the detection of extracellular matrix remodeling by targeting elastin has become an area of interest [61, 62]. Thus, molecular contrast agents may provide new opportunities for the identification of early atherosclerotic lesions as well as for the assessment of plaque vulnerability.

\section{Coronary MRA: Technical Considerations}

The small caliber of the coronary vessels, as well as the elevated anatomical variability, cardiac and respiratory motion pose major challenges to coronary MRA and require dedicated techniques for image quality optimization.

Ensuring Sufficient Image Contrast: Sequences, Spin Preparation and Contrast Agents

\section{Sequences}

The first approaches to coronary artery angiography were attempted by Edelman [63] and Manning [20] by 2dimensional (2D) gradient-echo techniques. One slice was acquired in 16 heartbeats during a single breath-hold. Patients could breathe between acquisitions. 3D techniques adopting a whole heart or target volume approach became feasible after the introduction of navigator techniques. 3D sequences allow an increase of signal-to-noise ratio (SNR), enabling higher spatial resolutions. The main disadvantage is the reduced contrast between blood and the myocardium due to the reduction of in-flow effects. Hence there is a need for contrast enhancing spin preparations techniques [17, 64] to be used in combination with 3D gradient echo (GRE) or steady-state-free-precession (SSFP) sequences [65]. At 1.5 Tesla, the latter are preferred to $\mathrm{T} 1$-weighted gradient echo sequences due to the higher SNR and improved contrast between blood and myocardium [65-67]. The use of SSFP sequences at $3 \mathrm{~T}$ is significantly limited by the prolongation of repetition times due to SAR limitations, the increased sensitivity to off-resonance effects and the need for higher flip angles. Gradient echo techniques appear as promising alternative [68].

\section{Contrast-Enhancing Spin Preparations}

For non-contrast enhanced imaging, spin preparation usually include fat suppression and T2-preparation. Fat saturation 
reduces the signal generated by the epicardial fat tissue, allowing a better delineation of the lumen of the coronaries $[63,64,69]$. In order to improve the contrast between the coronary lumen and the underlying myocardium, T2preparation techniques can be used $[17,69]$ to reduce the myocardial signal, as blood and myocardium have similar $\mathrm{T} 1$ but different $\mathrm{T} 2$.

T2-preparation also suppresses deoxygenated venous blood due to the shorter T2 of deoxygenated hemoglobin. Contrast enhanced techniques are therefore preferred for coronary vein imaging.

Other solutions, such as spin-locking [70] and magnetization transfer techniques (MTC) [64], have also been proposed to improve the contrast between the vessel lumen and the myocardium. In particular, MTC does not affect the signal from venous blood and can therefore be used to visualize the coronary venous system without administration of CA [71]. The application of CA can further improve the contrast between blood and the surrounding tissues.

\section{Contrast Agents}

Different types of CA have been tested for coronary MRA, ranging from extracellular CA [72] to blood-pool CA [73-76], and CA with weak albumin binding [77, 78]. The decision about the CA to use depends on the availability of different CA, as well as on the balance between lumenenhancing properties and the ability to provide information about myocardial scar as part of a combined ischemia/ CAD diagnostic imaging protocol. Extracellular CA generates limited contrast between the vessel lumen and the myocardium due to the rapid extravasation in the interstitial space. Blood-pool contrast agents offer the highest contrast between the vessel lumen and the surrounding tissues but may face limitations for late enhancement imaging [9].

Spin preparation for CA enhanced MRA usually includes a saturation [79] or inversion prepulse [80] instead of the T2 preparation. The difference in $\mathrm{T} 1$ recovery between blood and myocardium after CA administration allows the generation of high contrast images.

Improving Image Quality: Compensation of Cardiac and Respiratory Motion

\section{Compensation of Cardiac Motion: ECG Triggering}

To freeze cardiac motion, the acquisition of the $k$-space has to be synchronized with the cardiac cycle and needs to be limited to periods of minimal cardiac movement [81] occurring in end-systole (approximately $280-350 \mathrm{~ms}$ after the R wave) and in mid-diastole (immediately prior to atrial systole).
The choice of the trigger delay and the duration of the acquisition window depend on the patient's heart rate, on the sequence used and on the structure to visualize (arteries or veins). A free breathing high temporal resolution cine scan in the 4-chamber view can be used to determine the resting period [81]. This is generally longer for the left compared to the right coronary system. For this reason, the resting period of the RCA should be selected for the acquisition of whole-heart scans.

\section{Compensation of Respiratory Motion: Navigator}

Since three-dimensional (3D) acquisitions take a long period of time to complete, they require the synchronization of image acquisition with the respiratory cycle. Respiratory motion artifacts can be minimized by prospective real-time navigator gating and correction techniques [82, 83], in which a pencil beam one-dimensional (1D) navigator is used to monitor the craniocaudal motion of the right hemidiaphragm [84] immediately prior to coronary image acquisition. If the position of the diaphragm falls within a certain acceptance window (usually $3-5 \mathrm{~mm}$ wide), the acquired data acquired is used, otherwise is rejected and has to be re-measured in the subsequent cardiac cycle. An acceptance window of $5 \mathrm{~mm}$ usually allows an efficiency approaching $50 \%$ [85-87].

However, respiratory motion remains the major impediment in a substantial amount of patients undergoing coronary MRA. Usually, 1D navigator techniques assume a constant linear relationship between diaphragmatic and cardiac motion. This assumption is not correct in a significant percentage of subjects, leading to suboptimal results. Recently, the use of 2D navigator has been proposed, allowing for the prospective correction of translational motion both in craniocaudal and left-right direction [88] (Fig. 1).

The use of image based navigators that directly track cardiac motion, navigators that monitor the movement of epicardial fat [89], scanning in prone position [90, 91] and the use of abdominal or thoracic banding $[32,91]$ have also been proposed.

Of note, a lower sensitivity to motion and better image quality can also be obtained by improving the speed of image acquisition because of a shorter acquisition window or shorter overall data acquisition time [9]. To this purpose, different approaches have been proposed, such as faster encoding of k-space by echo planar imaging (EPI) [92, 93], or more efficient k-space sampling using spiral [94] or less motion sensitive $\mathrm{k}$-space sampling using radial trajectories [95]. However, none of these solutions have become an established technique for coronary MRA due to offresonance sensitivity (EPI, spiral) or signal-to-noise penalty (radial). 

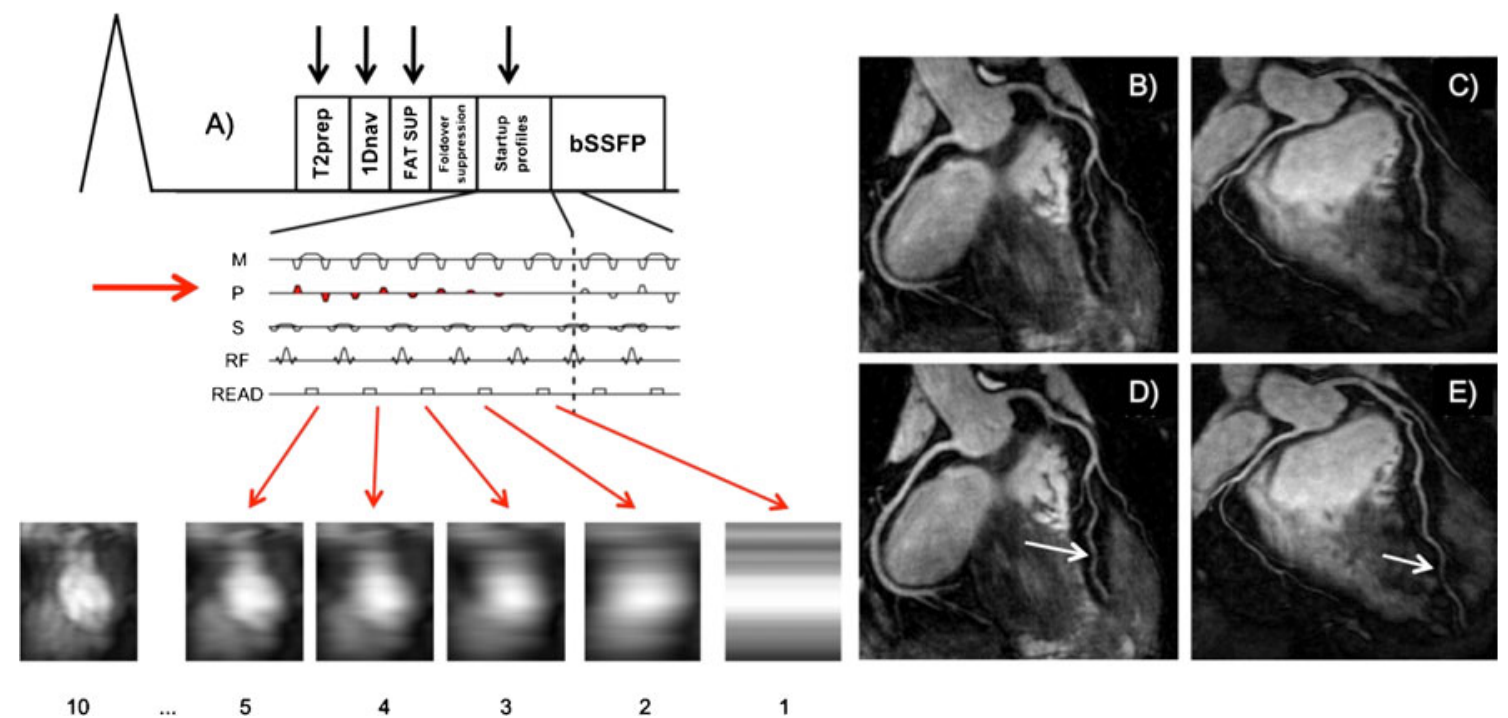

Fig. 1 (A) Sequence diagram of the 2D navigator (2Dnav) used for prospective motion correction (Adapted from Henningsson et al. [88]). The 2Dnav is acquired from the startup profiles of the sequence and uses fat suppression (spectrally selective inversion recovery, FAT SUP) and fold-over suppression to suppress signal from epicardial fat and to reduce fold-over artifacts. Reconstruction and image registration are performed immediately after 2Dnav acquisition, which yields

displacement information in FH and LR direction and is used for slice tracking. The $2 \mathrm{Dnav}$ can be combined with $2 \mathrm{D}$ or $3 \mathrm{D}$ gradient echo-based imaging sequences. The trailing 1D navigator is used for respiratory gating. The scanner gradients in measurement $(\mathrm{M})$, phase encoding $(\mathrm{P})$, and slice selection $(\mathrm{S})$ are shown for the sequence, along with the radiofrequency pulses. (B,C,D,E) Examples of right and left coronary artery visualized with the 2Dnav sequence

Parallel imaging techniques such as SENSE [96] or SMASH [97] can reduce the overall MRA acquisition time while maintaining image quality.

\section{Coronary Vein Imaging: Technical Considerations}

$\mathrm{T} 2$ preparation is not suitable for coronary vein imaging due to the shorter T2 values of deoxygenated venous blood. Current approaches to coronary vein MRA include non contrast-enhanced imaging by magnetization transfer (MTC) preparation [71, 98] or contrast enhanced MRA performed using blood-pool [6, 7, 41], extracellular [99], and CAs with weak albumin binding [100]. A slow infusion of a high relaxivity contrast agent during coronary vein MRA acquisition allows a good contrast between the vessel lumen and the surrounding tissues, with the possibility to acquire late gadolinium enhancement images after the redistribution of the contrast agent [100].

The optimal acquisition window for coronary vein imaging, as demonstrated by Nezafat and co-authors, is in end-systole, when the coronary vein diameter is maximal [71]. However, tachycardia and orthopnea cause difficulties with the ECG triggering and the asynchronous contraction of the LV makes the resting period different in independent segments of the chamber. In these patients, the acquisition parameters should therefore be adapted and data acquisition in end-diastole might be an alternative.

\section{Coronary Vessel Wall Imaging: Technical Considerations}

Utilizing black-blood techniques allows the latest clinical MR scanners to provide a detailed visualization of the coronary artery wall, either in cross-section or along the path of the vessel. Partial volume effects are minimized in cross-sectional view, providing images suitable for accurate quantification of the vessel wall thickness. A long-axis view of the vessel wall provides instead a more extensive visualization and typically allows assessment of the proximal $5 \mathrm{~cm}$ [9].

CA can be used for selective plaque visualization and delayed enhancement images can show focal or diffuse uptake of contrast agent indicating either a fibrous plaque or inflammation.

The current application of coronary vessel wall imaging is restricted to research purposes but with developments such as plaque-targeting agents used for clinical purposes it may become part of routine CAD risk assessment and monitoring of treatment response, especially if plaque-targeting agents become available for clinical use.

\section{Conclusions}

Cardiovascular magnetic resonance allows non-invasive and radiation free visualization of both the coronary arteries and 
veins, with the possibility of coronary vessel wall imaging. A major comparative advantage of MR is the possibility of a combined scanning protocol, investigating the anatomy of the coronaries as well as cardiac function, viability, stress perfusion and cardiac anatomy in the same study, providing valuable integrated information for patients with coronary artery disease and heart failure.

Coronary MRA may be indicated for the visualization of anomalies of the origin and course of the coronaries (class I indication) as well as to visualize coronary bypass grafts (class II indication) and may potentially be used to exclude CAD in selected populations of patients.

Ongoing technical developments continue to improve the robustness of the techniques.

Acknowledgments This manuscript is supported in part by the Wellcome Trust and EPSRC (grant number WT 088641/Z/09/Z).

Disclosure Conflicts of interest: A. Chiribiri: has received grant support from Philips Healthcare; R.M. Botnar: none; E. Nagel: has been a consultant for Bayer Healthcare; has received grant support from Philips $\&$ Bayer Healthcare; and has received travel/accommodations expenses covered or reimbursed from Bayer Healthcare.

Open Access This article is distributed under the terms of the Creative Commons Attribution License which permits any use, distribution, and reproduction in any medium, provided the original author(s) and the source are credited.

\section{References}

Papers of particular interest, published recently, have been highlighted as:

- Of importance

•- Of major importance

1. Ford ES, Ajani UA, Croft JB, Critchley JA, Labarthe DR, Kottke TE, et al. Explaining the decrease in U.S. Deaths from coronary disease, 1980-2000. N Engl J Med. 2007;356:2388-98.

2. Roger VL, Go AS, Lloyd-Jones DM, Adams RJ, Berry JD, Brown TM, et al. Heart disease and stroke statistics-2011 update: A report from the american heart association. Circulation. 2011;123:e18-209.

3. Patel MR, Peterson ED, Dai D, Brennan JM, Redberg RF, Anderson HV, et al. Low diagnostic yield of elective coronary angiography. N Engl J Med. 2010;362:886-95.

4. Kim WY, Danias PG, Stuber M, Flamm SD, Plein S, Nagel E, et al. Coronary magnetic resonance angiography for the detection of coronary stenoses. N Engl J Med. 2001;345:1863-9.

5. Spuentrup E, Botnar RM. Coronary magnetic resonance imaging: Visualization of the vessel lumen and the vessel wall and molecular imaging of arteriothrombosis. Eur Radiol. 2006;16:1-14.

6. Chiribiri A, Kelle S, Gotze S, Kriatselis C, Thouet T, Tangcharoen $\mathrm{T}$, et al. Visualization of the cardiac venous system using cardiac magnetic resonance. Am J Cardiol. 2008;101:407-12.

7. Chiribiri A, Kelle S, Kohler U, Tops LF, Schnackenburg B, Bonamini $\mathrm{R}$, et al. Magnetic resonance cardiac vein imaging: Relation to mitral valve annulus and left circumflex coronary artery. JACC Cardiovasc Imaging. 2008;1:729-38.
8. Hundley WG, Bluemke DA, Finn JP, Flamm SD, Fogel MA, Friedrich MG, et al. Accf/acr/aha/nasci/scmr 2010 expert consensus document on cardiovascular magnetic resonance: A report of the american college of cardiology foundation task force on expert consensus documents. J Am Coll Cardiol. 2010;55:2614-62.

9. Chiribiri A, Ishida M, Nagel E, Botnar RM. Coronary imaging with cardiovascular magnetic resonance: Current state of the art. Prog Cardiovasc Dis. 2011;54:240-52.

10. Boffano C, Chiribiri A, Cesarani F. Native whole-heart coronary imaging for the identification of anomalous origin of the coronary arteries. Int J Cardiol. 2009;137:e27-8.

11. Galjee MA, van Rossum AC, Doesburg T, van Eenige MJ, Visser CA. Value of magnetic resonance imaging in assessing patency and function of coronary artery bypass grafts. An angiographically controlled study. Circulation. 1996;93:660-6.

12. Jenkins JP, Love HG, Foster CJ, Isherwood I, Rowlands DJ. Detection of coronary artery bypass graft patency as assessed by magnetic resonance imaging. Br J Radiol. 1988;61:2-4.

13. Rubinstein RI, Askenase AD, Thickman D, Feldman MS, Agarwal JB, Helfant RH. Magnetic resonance imaging to evaluate patency of aortocoronary bypass grafts. Circulation. 1987;76:786-91.

14. White RD, Caputo GR, Mark AS, Modin GW, Higgins CB. Coronary artery bypass graft patency: Noninvasive evaluation with mr imaging. Radiology. 1987;164:681-6.

15. Vrachliotis TG, Bis KG, Aliabadi D, Shetty AN, Safian R, Simonetti O. Contrast-enhanced breath-hold $\mathrm{mr}$ angiography for evaluating patency of coronary artery bypass grafts. AJR Am J Roentgenol. 1997;168:1073-80.

16. Wintersperger BJ, von Smekal A, Engelmann MG, Knez A, Penzkofer HV, Laub G, et al. Contrast media enhanced magnetic resonance angiography for determining patency of a coronary bypass. A comparison with coronary angiography. Rofo. 1997;167:572-8.

17. Botnar RM, Stuber M, Danias PG, Kissinger KV, Manning WJ. Improved coronary artery definition with t2-weighted, free-breathing, three-dimensional coronary mra. Circulation. 1999;99:3139-48.

18. Hofman MB, Paschal CB, Li D, Haacke EM, van Rossum AC, Sprenger M. Mri of coronary arteries: $2 d$ breath-hold vs $3 \mathrm{~d}$ respiratory-gated acquisition. J Comput Assist Tomogr. 1995; 19:56-62.

19. Lobbes MB, Miserus RJ, Heeneman S, Passos VL, Mutsaers PH, Debernardi N, et al. Atherosclerosis: Contrast-enhanced mr imaging of vessel wall in rabbit model-comparison of gadofosveset and gadopentetate dimeglumine. Radiology. 2009;250:682-91.

20. Manning WJ, Li W, Boyle NG, Edelman RR. Fat-suppressed breath-hold magnetic resonance coronary angiography. Circulation. 1993;87:94-104.

21. Paschal CB, Haacke EM, Adler LP. Three-dimensional mr imaging of the coronary arteries: Preliminary clinical experience. J Magn Reson Imaging. 1993;3:491-500.

22. Post JC, van Rossum AC, Hofman MB, Valk J, Visser CA. Threedimensional respiratory-gated $\mathrm{mr}$ angiography of coronary arteries: Comparison with conventional coronary angiography. AJR Am J Roentgenol. 1996;166:1399-404.

23. Stuber M, Botnar RM, Danias PG, Sodickson DK, Kissinger KV, Van Cauteren M, et al. Double-oblique free-breathing high resolution three-dimensional coronary magnetic resonance angiography. J Am Coll Cardiol. 1999;34:524-31.

24. Scheidegger MB, Muller R, Boesiger P. Magnetic resonance angiography: Methods and its applications to the coronary arteries. Technol Health Care. 1994;2:255-65.

25. Bogaert J, Kuzo R, Dymarkowski S, Beckers R, Piessens J, Rademakers FE. Coronary artery imaging with real-time navigator three-dimensional turbo-field-echo $\mathrm{mr}$ coronary angiography: Initial experience. Radiology. 2003;226:707-16. 
26. Dewey M, Teige F, Schnapauff D, Laule M, Borges AC, Rutsch $\mathrm{W}$, et al. Combination of free-breathing and breathhold steadystate free precession magnetic resonance angiography for detection of coronary artery stenoses. J Magn Reson Imaging. 2006;23:674-81.

27. Jahnke C, Paetsch I, Nehrke K, Schnackenburg B, Gebker R, Fleck E, et al. Rapid and complete coronary arterial tree visualization with magnetic resonance imaging: Feasibility and diagnostic performance. Eur Heart J. 2005;26:2313-9.

28. Jahnke C, Paetsch I, Schnackenburg B, Bornstedt A, Gebker R, Fleck E, et al. Coronary $\mathrm{mr}$ angiography with steady-state free precession: Individually adapted breath-hold technique versus free-breathing technique. Radiology. 2004;232:669-76.

29. Maintz D, Aepfelbacher FC, Kissinger KV, Botnar RM, Danias PG, Heindel $\mathrm{W}$, et al. Coronary $\mathrm{mr}$ angiography: Comparison of quantitative and qualitative data from four techniques. AJR Am J Roentgenol. 2004;182:515-21.

30. Manning WJ, Li W, Edelman RR. A preliminary report comparing magnetic resonance coronary angiography with conventional angiography. N Engl J Med. 1993;328:828-32.

31. Ozgun M, Hoffmeier A, Kouwenhoven M, Botnar RM, Stuber $\mathrm{M}$, Scheld $\mathrm{HH}$, et al. Comparison of $3 \mathrm{~d}$ segmented gradient-echo and steady-state free precession coronary mri sequences in patients with coronary artery disease. AJR Am J Roentgenol. 2005;185:103-9.

32. Sakuma H, Ichikawa Y, Chino S, Hirano T, Makino K, Takeda K. Detection of coronary artery stenosis with whole-heart coronary magnetic resonance angiography. J Am Coll Cardiol. 2006; 48:1946-50.

33. Sakuma H, Ichikawa Y, Suzawa N, Hirano T, Makino K, Koyama $\mathrm{N}$, et al. Assessment of coronary arteries with total study time of less than 30 minutes by using whole-heart coronary $\mathrm{mr}$ angiography. Radiology. 2005;237:316-21.

34. - Schuetz GM, Zacharopoulou NM, Schlattmann P, Dewey M. Meta-analysis: Noninvasive coronary angiography using computed tomography versus magnetic resonance imaging. Ann Intern Med. 2010;152:167-77. Meta-analysis comparing the diagnostic accuracy of coronary MRA and CTA for the diagnosis of coronary stenosis.

35. • Kato S, Kitagawa K, Ishida N, Ishida M, Nagata M, Ichikawa $\mathrm{Y}$, et al. Assessment of coronary artery disease using magnetic resonance coronary angiography: A national multicenter trial. J Am Coll Cardiol. 2010;56:983-91. Multicenter national study on diagnostic accuracy of coronary MRA for the detection of coronary artery disease.

36. Miller JM, Rochitte CE, Dewey M, Arbab-Zadeh A, Niinuma H, Gottlieb I, et al. Diagnostic performance of coronary angiography by 64-row ct. N Engl J Med. 2008;359:2324-36.

37. Nagel E. Magnetic resonance coronary angiography: The condemned live longer. J Am Coll Cardiol. 2010;56:992-4.

38. •• Hamdan A, Asbach P, Wellnhofer E, Klein C, Gebker R, Kelle $\mathrm{S}$, et al. A prospective study for comparison of $\mathrm{mr}$ and ct imaging for detection of coronary artery stenosis. JACC Cardiovasc Imaging. 2011;4:50-61. Single-center study comparing the diagnostic accuracy of coronary MRA and CTA for the detection of coronary stenosis.

39. Duckett SG, Ginks M, Shetty AK, Knowles BR, Totman JJ, Chiribiri A, et al. Realtime fusion of cardiac magnetic resonance imaging and computed tomography venography with $\mathrm{x}$-ray fluoroscopy to aid cardiac resynchronisation therapy implantation in patients with persistent left superior vena cava. Europace. 2011;13:285-6.

40. Duckett SG, Ginks MR, Knowles BR, Ma Y, Shetty A, Bostock J, et al. Advanced image fusion to overlay coronary sinus anatomy with real-time fluoroscopy to facilitate left ventricular lead implantation in crt. Pacing Clin Electrophysiol. 2011;34:226-34.
41. Rasche V, Binner L, Cavagna F, Hombach V, Kunze M, Spiess J, et al. Whole-heart coronary vein imaging: A comparison between non-contrast-agent- and contrast-agent-enhanced visualization of the coronary venous system. Magn Reson Med. 2007;57:1019-26.

42. Botnar RM, Stuber M, Kissinger KV, Kim WY, Spuentrup E, Manning WJ. Noninvasive coronary vessel wall and plaque imaging with magnetic resonance imaging. Circulation. 2000;102:2582-7.

43. Fayad ZA, Fuster V, Fallon JT, Jayasundera T, Worthley SG, Helft G, et al. Noninvasive in vivo human coronary artery lumen and wall imaging using black-blood magnetic resonance imaging. Circulation. 2000;102:506-10.

44. Edelman RR, Chien D, Kim D. Fast selective black blood mr imaging. Radiology. 1991;181:655-60.

45. Botnar RM, Stuber M, Lamerichs R, Smink J, Fischer SE, Harvey $\mathrm{P}$, et al. Initial experiences with in vivo right coronary artery human mr vessel wall imaging at 3 tesla. J Cardiovasc Magn Reson. 2003;5:589-94.

46. Botnar RM, Kim WY, Bornert P, Stuber M, Spuentrup E, Manning WJ. 3d coronary vessel wall imaging utilizing a local inversion technique with spiral image acquisition. Magn Reson Med. 2001;46:848-54.

47. Katoh M, Spuentrup E, Buecker A, Schaeffter T, Stuber M, Gunther RW, et al. Mri of coronary vessel walls using radial kspace sampling and steady-state free precession imaging. AJR Am J Roentgenol. 2006;186:S401-6.

48. Kim WY, Stuber M, Bornert P, Kissinger KV, Manning WJ, Botnar RM. Three-dimensional black-blood cardiac magnetic resonance coronary vessel wall imaging detects positive arterial remodeling in patients with nonsignificant coronary artery disease. Circulation. 2002;106:296-9.

49. Kim WY, Astrup AS, Stuber M, Tarnow L, Falk E, Botnar RM, et al. Subclinical coronary and aortic atherosclerosis detected by magnetic resonance imaging in type 1 diabetes with and without diabetic nephropathy. Circulation. 2007;115:228-35.

50. Jansen CH, Perera D, Makowski MR, Wiethoff AJ, Phinikaridou A, Razavi RM, et al. Detection of intracoronary thrombus by magnetic resonance imaging in patients with acute myocardial infarction. Circulation. 2011;124:416-24.

51. Yeon SB, Sabir A, Clouse M, Martinezclark PO, Peters DC, Hauser TH, et al. Delayed-enhancement cardiovascular magnetic resonance coronary artery wall imaging: Comparison with multislice computed tomography and quantitative coronary angiography. J Am Coll Cardiol. 2007;50:441-7.

52. Ibrahim T, Makowski MR, Jankauskas A, Maintz D, Karch M, Schachoff $S$, et al. Serial contrast-enhanced cardiac magnetic resonance imaging demonstrates regression of hyperenhancement within the coronary artery wall in patients after acute myocardial infarction. JACC Cardiovasc Imaging. 2009;2:580-8.

53. Puntmann VO, D'Cruz D, Taylor P, Hussain T, Indermuehle A, Butzbach $\mathrm{B}$, et al. Contrast enhancement imaging in coronary arteries in patients with systemic lupus erythematosus. J Cardiovasc Magn Reson. 2012;14:178.

54. Phinikaridou A, Andia ME, Protti A, Indermuehle A, Shah A, Smith A, et al. Noninvasive magnetic resonance imaging evaluation of endothelial permeability in murine atherosclerosis using an albumin-binding contrast agent. Circulation. 2012;126:707-19.

55. Kooi ME, Cappendijk VC, Cleutjens KB, Kessels AG, Kitslaar PJ, Borgers M, et al. Accumulation of ultrasmall superparamagnetic particles of iron oxide in human atherosclerotic plaques can be detected by in vivo magnetic resonance imaging. Circulation. 2003;107:2453-8.

56. Tang TY, Howarth SP, Miller SR, Graves MJ, Patterson AJ. JM UK-I, Li ZY, Walsh SR, Brown AP, Kirkpatrick PJ, Warburton 
EA, Hayes PD, Varty K, Boyle JR, Gaunt ME, Zalewski A, Gillard JH. The atheroma (atorvastatin therapy: Effects on reduction of macrophage activity) study. Evaluation using ultrasmall superparamagnetic iron oxide-enhanced magnetic resonance imaging in carotid disease. J Am Coll Cardiol. 2009;53:2039-50.

57. Nahrendorf M, Jaffer FA, Kelly KA, Sosnovik DE, Aikawa E, Libby $P$, et al. Noninvasive vascular cell adhesion molecule-1 imaging identifies inflammatory activation of cells in atherosclerosis. Circulation. 2006;114:1504-11.

58. Nahrendorf M, Keliher E, Panizzi P, Zhang H, Hembrador S, Figueiredo JL, et al. $18 \mathrm{f}-4 \mathrm{v}$ for pet-ct imaging of vcam-1 expression in atherosclerosis. JACC Cardiovasc Imaging. 2009;2:1213-22.

59. Botnar RM, Buecker A, Wiethoff AJ, Parsons Jr EC, Katoh M, Katsimaglis $\mathrm{G}$, et al. In vivo magnetic resonance imaging of coronary thrombosis using a fibrin-binding molecular magnetic resonance contrast agent. Circulation. 2004;110:1463-6.

60. Botnar RM, Perez AS, Witte S, Wiethoff AJ, Laredo J, Hamilton $\mathrm{J}$, et al. In vivo molecular imaging of acute and subacute thrombosis using a fibrin-binding magnetic resonance imaging contrast agent. Circulation. 2004;109:2023-9.

61. Makowski MR, Wiethoff AJ, Blume U, Cuello F, Warley A, Jansen $\mathrm{CH}$, et al. Assessment of atherosclerotic plaque burden with an elastin-specific magnetic resonance contrast agent. Nat Med. 2011;17:383-8.

62. von Bary C, Makowski M, Preissel A, Keithahn A, Warley A, Spuentrup E, et al. Mri of coronary wall remodeling in a swine model of coronary injury using an elastin-binding contrast agent. Circ Cardiovasc Imaging. 2011;4:147-55.

63. Edelman RR, Manning WJ, Burstein D, Paulin S. Coronary arteries: Breath-hold mr angiography. Radiology. 1991;181:641-3.

64. Li D, Paschal CB, Haacke EM, Adler LP. Coronary arteries: Three-dimensional $\mathrm{mr}$ imaging with fat saturation and magnetization transfer contrast. Radiology. 1993;187:401-6.

65. Deshpande VS, Shea SM, Laub G, Simonetti OP, Finn JP, Li D. $3 \mathrm{~d}$ magnetization-prepared true-fisp: A new technique for imaging coronary arteries. Magn Reson Med. 2001;46:494-502.

66. Giorgi B, Dymarkowski S, Maes F, Kouwenhoven M, Bogaert J. Improved visualization of coronary arteries using a new three-dimensional submillimeter $\mathrm{mr}$ coronary angiography sequence with balanced gradients. AJR Am J Roentgenol. 2002;179:901-10.

67. Spuentrup E, Bornert P, Botnar RM, Groen JP, Manning WJ, Stuber M. Navigator-gated free-breathing three-dimensional balanced fast field echo (truefisp) coronary magnetic resonance angiography. Invest Radiol. 2002;37:637-42.

68. Kaul MG, Stork A, Bansmann PM, Nolte-Ernsting C, Lund GK, Weber $\mathrm{C}$, et al. Evaluation of balanced steady-state free precession (truefisp) and k-space segmented gradient echo sequences for $3 \mathrm{~d}$ coronary $\mathrm{mr}$ angiography with navigator gating at 3 tesla. Rofo. 2004;176:1560-5.

69. Brittain JH, Hu BS, Wright GA, Meyer CH, Macovski A, Nishimura DG. Coronary angiography with magnetizationprepared t2 contrast. Magn Reson Med. 1995;33:689-96.

70. Dixon WT, Oshinski JN, Trudeau JD, Arnold BC, Pettigrew RI. Myocardial suppression in vivo by spin locking with composite pulses. Magn Reson Med. 1996;36:90-4.

71. Nezafat R, Han Y, Peters DC, Herzka DA, Wylie JV, Goddu B, et al. Coronary magnetic resonance vein imaging: Imaging contrast, sequence, and timing. Magn Reson Med. 2007;58:1196-206.

72. Regenfus M, Ropers D, Achenbach S, Kessler W, Laub G, Daniel WG, et al. Noninvasive detection of coronary artery stenosis using contrast-enhanced three-dimensional breath-hold magnetic resonance coronary angiography. J Am Coll Cardiol. 2000;36:44-50.
73. Huber ME, Paetsch I, Schnackenburg B, Bornstedt A, Nagel E, Fleck E, et al. Performance of a new gadolinium-based intravascular contrast agent in free-breathing inversion-recovery $3 \mathrm{~d}$ coronary mra. Magn Reson Med. 2003;49:115-21.

74. Kelle S, Thouet T, Tangcharoen T, Nassenstein K, Chiribiri A, Paetsch I, et al. Whole-heart coronary magnetic resonance angiography with ms-325 (gadofosveset). Med Sci Monit. 2007;13: CR469-74.

75. Li D, Dolan RP, Walovitch RC, Lauffer RB. Three-dimensional mri of coronary arteries using an intravascular contrast agent. Magn Reson Med. 1998;39:1014-8.

76. Tang L, Merkle N, Schar M, Korosoglou G, Solaiyappan M, Hombach V, et al. Volume-targeted and whole-heart coronary magnetic resonance angiography using an intravascular contrast agent. J Magn Reson Imaging. 2009;30:1191-6.

77. Liu X, Bi X, Huang J, Jerecic R, Carr J, Li D. Contrast-enhanced whole-heart coronary magnetic resonance angiography at $3.0 \mathrm{t}$ : Comparison with steady-state free precession technique at $1.5 \mathrm{t}$. Invest Radiol. 2008;43:663-8.

78. Nassenstein K, Breuckmann F, Hunold P, Barkhausen J, Schlosser T. Magnetic resonance coronary angiography: Comparison between a gd-bopta- and a gd-dtpa-enhanced spoiled gradient-echo sequence and a non-contrast-enhanced steady-state free-precession sequence. Acta Radiol. 2009;50:40611.

79. Goldfarb JW, Edelman RR. Coronary arteries: Breath-hold, gadolinium-enhanced, three-dimensional $\mathrm{mr}$ angiography. Radiology. 1998;206:830-4.

80. Stuber M, Botnar RM, Danias PG, McConnell MV, Kissinger $\mathrm{KV}$, Yucel EK, et al. Contrast agent-enhanced, free-breathing, three-dimensional coronary magnetic resonance angiography. J Magn Reson Imaging. 1999;10:790-9.

81. Kim WY, Stuber M, Kissinger KV, Andersen NT, Manning WJ, Botnar RM. Impact of bulk cardiac motion on right coronary mr angiography and vessel wall imaging. J Magn Reson Imaging. 2001;14:383-90.

82. Ehman RL, Felmlee JP. Adaptive technique for high-definition mr imaging of moving structures. Radiology. 1989;173:255-63.

83. Nehrke K, Bornert P, Groen J, Smink J, Bock JC. On the performance and accuracy of $2 \mathrm{~d}$ navigator pulses. Magn Reson Imaging. 1999; 17:1173-81.

84. Wang Y, Riederer SJ, Ehman RL. Respiratory motion of the heart: Kinematics and the implications for the spatial resolution in coronary imaging. Magn Reson Med. 1995;33:713-9.

85. Danias PG, McConnell MV, Khasgiwala VC, Chuang ML, Edelman RR, Manning WJ. Prospective navigator correction of image position for coronary $\mathrm{mr}$ angiography. Radiology. 1997;203:733-6.

86. Danias PG, Stuber M, Botnar RM, Kissinger KV, Edelman RR, Manning WJ. Relationship between motion of coronary arteries and diaphragm during free breathing: Lessons from real-time $\mathrm{mr}$ imaging. AJR Am J Roentgenol. 1999;172:1061-5.

87. Nagel E, Bornstedt A, Schnackenburg B, Hug J, Oswald H, Fleck E. Optimization of realtime adaptive navigator correction for $3 \mathrm{~d}$ magnetic resonance coronary angiography. Magn Reson Med. 1999;42:408-11.

88. Henningsson M, Smink J, Razavi R, Botnar RM. Prospective respiratory motion correction for coronary $\mathrm{mr}$ angiography using a 2d image navigator. Magn Reson Med. 2012. doi:10.1002/ mrm. 24280 .

89. Manke D, Nehrke K, Bornert P. Novel prospective respiratory motion correction approach for free-breathing coronary $\mathrm{mr}$ angiography using a patient-adapted affine motion model. Magn Reson Med. 2003;50:122-31.

90. Huber S, Bornstedt A, Schnackenburg B, Paetsch I, Fleck E, Nagel E. The impact of different positions and thoracial restrains 
on respiratory induced cardiac motion. J Cardiovasc Magn Reson. 2006;8:483-8.

91. Stuber M, Danias PG, Botnar RM, Sodickson DK, Kissinger KV, Manning WJ. Superiority of prone position in free-breathing $3 \mathrm{~d}$ coronary mra in patients with coronary disease. J Magn Reson Imaging. 2001;13:185-91.

92. Bhat H, Yang Q, Zuehlsdorff S, Li K, Li D. Contrast-enhanced whole-heart coronary magnetic resonance angiography at $3 \mathrm{t}$ using interleaved echo planar imaging. Invest Radiol. 2010;45:458-64.

93. Slavin GS, Riederer SJ, Ehman RL. Two-dimensional multishot echo-planar coronary $\mathrm{mr}$ angiography. Magn Reson Med. 1998;40:883-9.

94. Bornert P, Stuber M, Botnar RM, Kissinger KV, Koken P, Spuentrup E, et al. Direct comparison of $3 \mathrm{~d}$ spiral vs. Cartesian gradient-echo coronary magnetic resonance angiography. Magn Reson Med. 2001;46:789-94.

95. Priest AN, Bansmann PM, Mullerleile K, Adam G. Coronary vessel-wall and lumen imaging using radial $\mathrm{k}$-space acquisition with mri at 3 tesla. Eur Radiol. 2007;17:339-46.
96. Pruessmann KP, Weiger M, Scheidegger MB, Boesiger P. Sense: Sensitivity encoding for fast mri. Magn Reson Med. 1999;42:952-62.

97. Sodickson DK, Manning WJ. Simultaneous acquisition of spatial harmonics (smash): Fast imaging with radiofrequency coil arrays. Magn Reson Med. 1997;38:591-603.

98. Stoeck CT, Han Y, Peters DC, Hu P, Yeon SB, Kissinger $\mathrm{KV}$, et al. Whole heart magnetization-prepared steady-state free precession coronary vein mri. J Magn Reson Imaging. 2009;29:1293-9.

99. Younger JF, Plein S, Crean A, Ball SG, Greenwood JP. Visualization of coronary venous anatomy by cardiovascular magnetic resonance. J Cardiovasc Magn Reson. 2009;11:26.

100. Duckett SG, Chiribiri A, Ginks MR, Sinclair S, Knowles BR, Botnar $\mathrm{R}$, et al. Cardiac mri to investigate myocardial scar and coronary venous anatomy using a slow infusion of dimeglumine gadobenate in patients undergoing assessment for cardiac resynchronization therapy. J Magn Reson Imaging. 2011;33:87-95. 